\title{
Distant metastasis in triple-negative breast cancer
}

\author{
L. M. TSENG ${ }^{1,2}$, N. C. HSU ${ }^{3}$, S. C. CHEN ${ }^{4}$, Y. S. LU ${ }^{5,6}$, C. H. LIN ${ }^{5}$, D. Y. CHANG ${ }^{5}$, H. LI ${ }^{7}$, Y. C. LIN ${ }^{8,9}$, H. K. CHANG $^{8,9}$, T. C. CHAO ${ }^{10}$, F. OUYANG ${ }^{11,13}$, \\ M. F. $\operatorname{HOU}^{11,12,13,14, *}$
}

${ }^{1}$ Department of Surgery, Taipei Veterans General Hospital, Taipei, Taiwan; ${ }^{2}$ School of Medicine, National Yang-Ming University, Taipei, Taiwan; ${ }^{3}$ Graduate Institute of Medicine, Kaohsiung Medical University, Kaohsiung, Taiwan; ${ }^{4}$ Department of Surgery, Chang Gung Memorial Hospital, Taoyuan, Taiwan; ${ }^{5}$ Department of Oncology, National Taiwan University Hospital, Taipei, Taiwan; ${ }^{6}$ Department of Internal Medicine, National Taiwan University College of Medicine, Taipei, Taiwan; ${ }^{7}$ DUKE-NUS Graduate Medical School, Singapore; ${ }^{8}$ Division of Medical Oncology, Department of Medicine, Chang Gung Memorial Hospital, Taipei, Taiwan; ${ }^{9}$ Chang Gung University Medical College, Taoyuan, Taiwan; ${ }^{10}$ Department of Internal Medicine, Division of Hematology and Oncology, Taipei Veterans General Hospital, Taipei, Taiwan; ${ }^{11}$ Cancer Center, Kaohsiung Medical University Hospital, Kaohsiung, Taiwan; ${ }^{12}$ National Sun Yat-Sen University-Kaohsiung Medical University Joint Research Center, Kaohsiung, Taiwan; ${ }^{13}$ Division of General \& Gastroenterological Surgery, Department of Surgery, Kaohsiung Medical University Hospital, Kaohsiung, Taiwan; ${ }^{14}$ Kaohsiung Municipal Ta-Tung Hospital, Kaohsiung, Taiwan

${ }^{*}$ Correspondence: mifeho@kmu.edu.tw

Received August 31, 2012 / Accepted January 7, 2013

\begin{abstract}
Triple-negative breast cancer (TNBC) relapses more frequently than hormone receptor-positive subtypes and is often associated with poor outcomes. This retrospective study reviewed the pattern of distant metastasis with regard to survival in patients with TNBC. A total of 205 TNBC patients were analyzed. TNBC patients with lung metastases had the longest median post-metastatic OS (with 95\% confidence interval) of 16.6 (10.3-22.9) months, followed by the bone, 16.3 (11.7-20.8) months, the liver, 8.9 (3.5-14.4) months, the pleura, 7.5 (2.8-12.3) months, and the brain, 4.3 (0.6-8.0) months. Kaplan-Meier plots indicated that TNBC patients with metastatic spread to brain, liver, and pleural had poorer post-metastatic OS rate than patients with lung metastases ( $p=0.001$, 0.004 , and 0.029 , respectively). Moreover, brain and liver metastases correlated significantly with poorer post-metastatic OS as compared to bone metastasis ( $\mathrm{p}=0.004$ and 0.011 , respectively). Route of first metastasis correlated significantly with survival of TNBC patients with brain metastases being the poorest survival indicator, followed by metastases to liver, pleura, bone, and lung.
\end{abstract}

Key words: triple-negative breast cancer, metastasis, survival

Breast cancer is the most prevalent cancer and ranks second in cancer mortality in women affecting approximately a million worldwide. Breast cancer is a highly heterogeneous disease consisting of various subtypes each carries a distinct molecular and pathologic profile [1-4]. Triple-negative breast cancer (TNBC) is a subtype of breast cancer that lacks the expression of estrogen and progesterone receptors (ER/PR), and lacks overexpression or amplification of HER2/NEU gene. TNBC often share similar biological features with basal-like carcinomas and is associated with poor clinical outcome, high rates of recurrence following chemotherapy, and metastasis [59]. Although novel targeted agents, including hormonal and HER2-directed therapies, are ineffective in this setting, an array of chemotherapeutic agents is suitable for use in patients with TNBC [10-12]. Anthracycline and taxane (AT) are the preferred first-line treatment for TNBC in Taiwan. Despite of the treatment, however, most TNBC patients relapse and progress quickly on subsequent line palliative therapy $[13,14]$.

The gene expression and differentiation of breast carcinoma have been shown to correlate with the sites to which tumors metastasize [15-19]. A higher incidence of visceral metastases was reported in patients with TNBC as compared with nonTNBC patients $[8,20]$. Moreover, it has been reported that the excess risk of distant metastases in TNBC is attributed to high incidence of visceral metastases [21].

The aim of this study was to investigate the pattern of metastatic spread of TNBC patients with regard to survival.

\section{Patients and methods}

Patients diagnosed with TNBC between January 1, 2001 and December 31, 2006 were selected and analyzed from Cancer 
registry database of four medical centers (National Taiwan University Hospital, Chang Gung Memorial Hospital Linkou Branch, Veterans General Hospital Taipei, and Kaohsiung Medical University Hospital) in Taiwan. This study was approved by the Institutional Review Board of the four medical centers. Written informed consent was waived due to the retrospective nature of the investigation. Distant metastasis was defined as clinical evidence of distant disease based on clinical and/or radiographic findings. Overall survival (OS) was calculated from the time of initial diagnosis to death of any

Table 1. Triple negative breast cancer patients' demographics and disease characteristics.

\begin{tabular}{|c|c|c|}
\hline \multirow{2}{*}{ Characteristic } & \multicolumn{2}{|c|}{ Number of Subjects } \\
\hline & $\mathrm{N}=205$ & $\%$ \\
\hline \multicolumn{3}{|c|}{ Age (years) at first breast cancer diagnosis } \\
\hline Mean(SD) & $49.3(11.3)$ & \\
\hline (min, median, $\max$ ) & $(25,48,81)$ & \\
\hline \multicolumn{3}{|c|}{ Age (years) at first distal metastasis } \\
\hline Mean(SD) & $51.5(10.9)$ & \\
\hline (min, median, $\max$ ) & $(26,51,82)$ & \\
\hline \multicolumn{3}{|l|}{ Stage } \\
\hline I & 9 & 4.4 \\
\hline II & 63 & 30.7 \\
\hline III & 108 & 52.7 \\
\hline IV & 25 & 12.2 \\
\hline \multicolumn{3}{|l|}{ Lymph Node } \\
\hline Positive & 128 & 62.4 \\
\hline Negative & 43 & 21 \\
\hline Unknown & 34 & 16.6 \\
\hline \multicolumn{3}{|l|}{ Distal Metastasis Site } \\
\hline Bone & 47 & 22.9 \\
\hline Lung & 41 & 20 \\
\hline Brain & 14 & 6.8 \\
\hline Liver & 28 & 13.7 \\
\hline Pleura & 18 & 8.8 \\
\hline Mixed & 37 & \\
\hline Bone+Brain & 3 & 1.5 \\
\hline Bone+Lung & 4 & 2 \\
\hline Bone+Liver & 7 & 3.4 \\
\hline Bone+Pleura & 1 & 0.5 \\
\hline Bone+Others & 1 & 0.5 \\
\hline Bone+Lung+Brain & 1 & 0.5 \\
\hline Bone+Lung+Liver & 5 & 2.4 \\
\hline Bone+Lung+Pleura & 1 & 0.5 \\
\hline Bone+Liver+Pleura & 1 & 0.5 \\
\hline Lung+Liver & 7 & 3.4 \\
\hline Lung+Pleura & 1 & 0.5 \\
\hline Lung+Others & 1 & 0.5 \\
\hline Lung+Pleura+Others & 1 & 0.5 \\
\hline Liver+Pleura & 3 & 1.5 \\
\hline Others & 8 & 3.9 \\
\hline No & 12 & 5.9 \\
\hline
\end{tabular}

cause. Post-metastatic OS was defined as the date of first distant metastasis to death of any cause. Patients still alive at the end of the study were censored at the date of last follow-up. Data from medical charts were retrieved, and the patients' outcomes were followed until June 30, 2008 or date of death, whichever occurred first. Cases which lacked survival data or complete treatment history were excluded from the analysis. The 95\% confidence interval was calculated using the Clopper-Pearson method. Post-metastatic OS were assessed by Kaplan-Meier analysis using log-rank test. All statistical calculations were done using SPSS version 17.0 for windows (SPSS, Inc., Chicago, IL). $P<0.05$ was considered significant.

\section{Results}

A total of 205 patients who were diagnosed with TNBC at the four medical centers in Taiwan were analyzed. The disease characteristic that includes the first site(s) of distant metastasis is listed in Table 1. The median OS was 33.9 months for all 205 TNBC patients; OS rates for 1-year, 3-year, and 5-year were $91.7 \%, 46.5 \%$, and $26.5 \%$, respectively (Figure 1). 193 of 205 (94.1\%) patients presented with distant metastases. The most common site for the first metastasis to occur was the

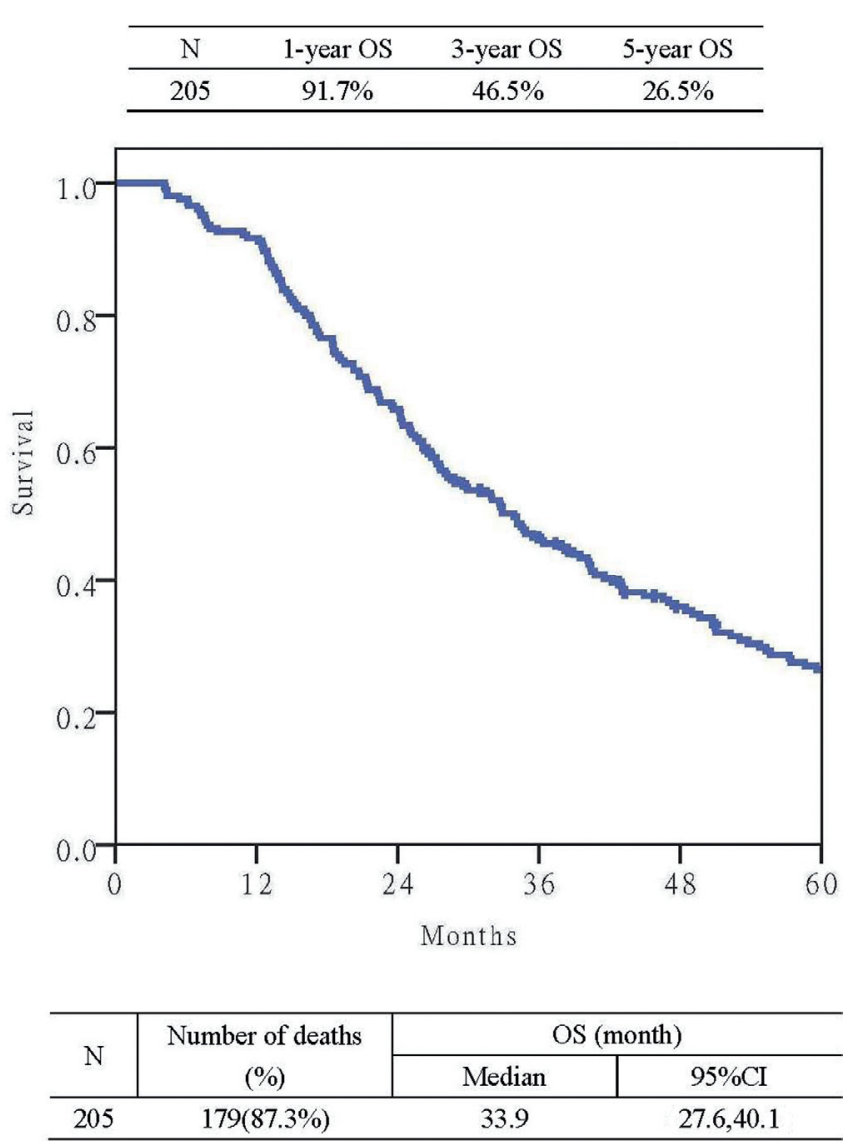

Figure 1. Kaplan-Meier analysis for overall survival of the 205 patients with triple-negative breast cancer. 


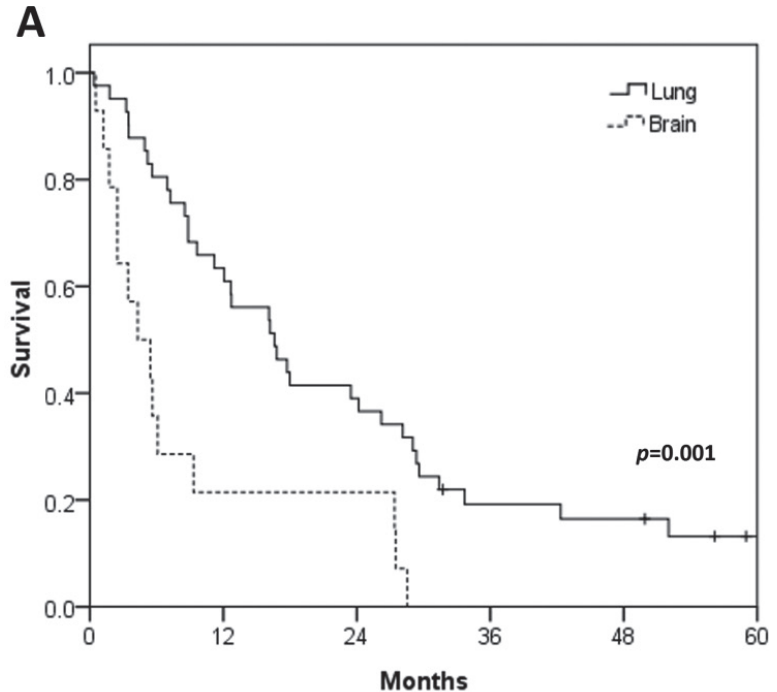

B
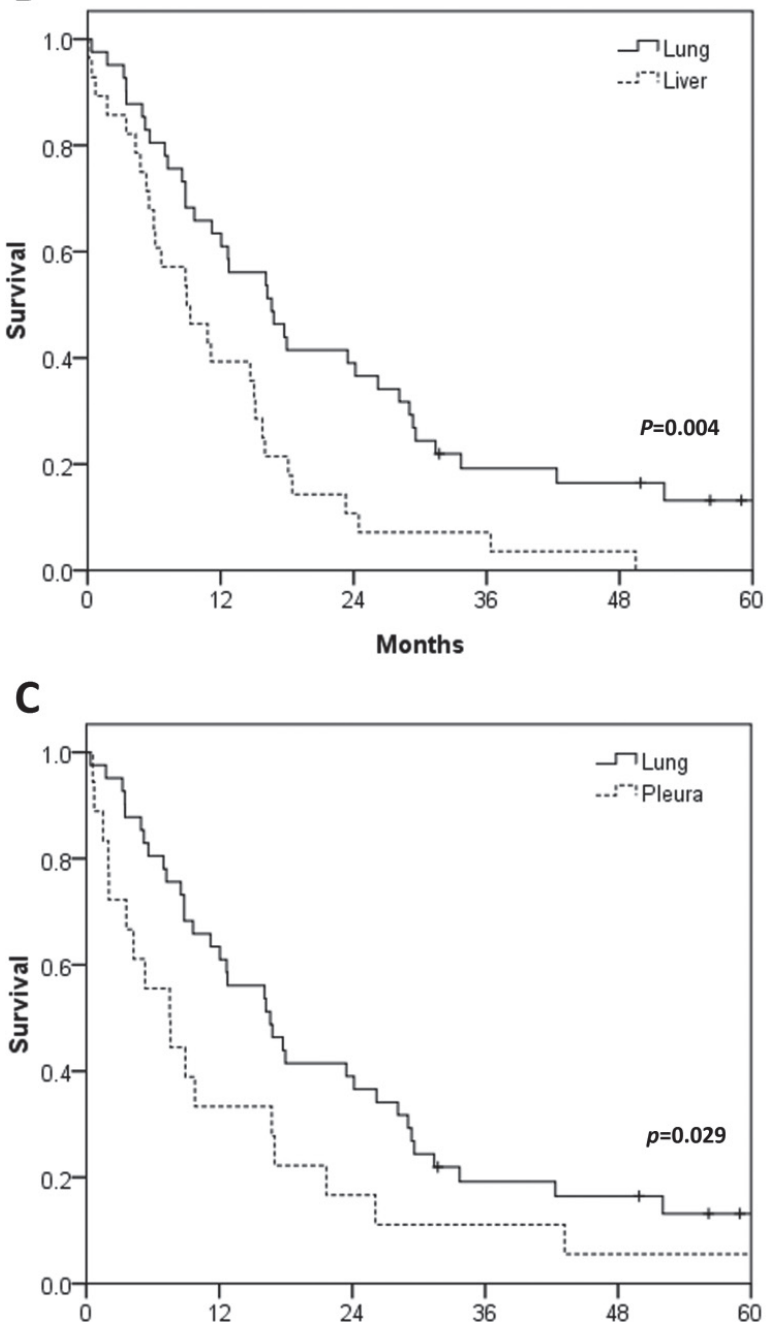

Figure 2. Kaplan-Meier overall survival (OS) curves for triple-negative breast cancer patients as a function of first metastatic site. A) lung versus brain $B$ ) lung versus liver $C$ ) lung versus pleura. bone (22.9\%), followed by lung (20.0\%), liver (13.7\%), pleura (8.8\%), and brain (6.8\%). Thirty-seven patients (18.0\%) had evidence of synchronous metastases of multiple sites at time of initial metastasis. We calculated and compared the postmetastatic OS of TNBC patients according to the five most common first-metastatic site which included the bone, lung, liver, pleural, and brain. For the purpose of elucidating the site of metastases with regard to survival, the 37 cases with multiple metastatic sites were not included in the survival analyses. TNBC patients with the lung as the first metastatic site had the longest median post-metastatic OS (with 95\% confidence interval) of 16.6 (10.3-22.9) months, followed by the bone, 16.3 (11.7-20.8) months, the liver, 8.9 (3.5-14.4) months, the pleura, $7.5(2.8-12.3)$ months, and the brain, 4.3 (0.6-8.0) months (Table 2). Kaplan-Meier survival analysis indicated that patients with metastatic spread to the brain, liver, and pleura exhibited poorer post-metastatic OS than patients with lung metastases (Figure 2). On the other hand, brain and liver metastases correlated significantly with poorer post-metastatic OS as compared to bone metastasis. There was no significant difference in post-metastatic OS between bone and either lung or pleura metastases (Figure 3).

Table 2. Overall survival of triple negative breast cancer patients by the first site (organ) of metastasis.

\begin{tabular}{|c|c|c|c|c|c|}
\hline \multirow{2}{*}{ Organ } & \multirow{2}{*}{$\mathrm{N}=148$} & \multirow{2}{*}{$\begin{array}{c}\text { Number of } \\
\text { deaths(\%) }\end{array}$} & \multicolumn{3}{|c|}{ Post-Metastatic OS (month) } \\
\hline & & & Median & $95 \% \mathrm{CI}$ & $p$ \\
\hline Bone & 47 & $39(83.0 \%)$ & 16.3 & $(11.7,20.8)$ & \multirow{5}{*}{$0.001^{*}$} \\
\hline Lung & 41 & $36(87.8 \%)$ & 16.6 & $(10.3,22.9)$ & \\
\hline Brain & 14 & $14(100 \%)$ & 4.3 & $(0.6,8.0)$ & \\
\hline Liver & 28 & $28(100 \%)$ & 8.9 & $(3.5,14.4)$ & \\
\hline Pleura & 18 & $18(100 \%)$ & 7.5 & $(2.8,12.3)$ & \\
\hline Bone & 47 & $39(83.0 \%)$ & 16.3 & $(11.7,20.8)$ & \multirow{2}{*}{0.732} \\
\hline Lung & 41 & $36(87.8 \%)$ & 16.6 & $(10.3,22.9)$ & \\
\hline Bone & 47 & $39(83.0 \%)$ & 16.3 & $(11.7,20.8)$ & \multirow{2}{*}{$0.004^{*}$} \\
\hline Brain & 14 & $14(100 \%)$ & 4.3 & $(0.6,8.0)$ & \\
\hline Bone & 47 & $39(83.0 \%)$ & 16.3 & $(11.7,20.8)$ & \multirow{2}{*}{$0.011^{*}$} \\
\hline Liver & 28 & $28(100 \%)$ & 8.9 & $(3.5,14.4)$ & \\
\hline Bone & 47 & $39(83.0 \%)$ & 16.3 & $(11.7,20.8)$ & \multirow{2}{*}{0.081} \\
\hline Pleura & 18 & $18(100 \%)$ & 7.5 & $(2.8,12.3)$ & \\
\hline Lung & 41 & $36(87.8 \%)$ & 16.6 & $(10.3,22.9)$ & \multirow{2}{*}{$0.001^{*}$} \\
\hline Brain & 14 & $14(100 \%)$ & 4.3 & $(0.6,8.0)$ & \\
\hline Lung & 41 & $36(87.8 \%)$ & 16.6 & $(10.3,22.9)$ & \multirow{2}{*}{$0.004^{*}$} \\
\hline Liver & 28 & $28(100 \%)$ & 8.9 & $(3.5,14.4)$ & \\
\hline Lung & 41 & $36(87.8 \%)$ & 16.6 & $(10.3,22.9)$ & \multirow{2}{*}{$0.029^{*}$} \\
\hline Pleura & 18 & $18(100 \%)$ & 7.5 & $(2.8,12.3)$ & \\
\hline Brain & 14 & $14(100 \%)$ & 4.3 & $(0.6,8.0)$ & \multirow{2}{*}{0.397} \\
\hline Liver & 28 & $28(100 \%)$ & 8.9 & $(3.5,14.4)$ & \\
\hline Brain & 14 & $14(100 \%)$ & 4.3 & $(0.6,8.0)$ & \multirow{2}{*}{0.492} \\
\hline Pleura & 18 & $18(100 \%)$ & 7.5 & $(2.8,12.3)$ & \\
\hline Liver & 28 & $28(100 \%)$ & 8.9 & $(3.5,14.4)$ & \multirow{2}{*}{0.773} \\
\hline Pleura & 18 & $18(100 \%)$ & 7.5 & $(2.8,12.3)$ & \\
\hline
\end{tabular}



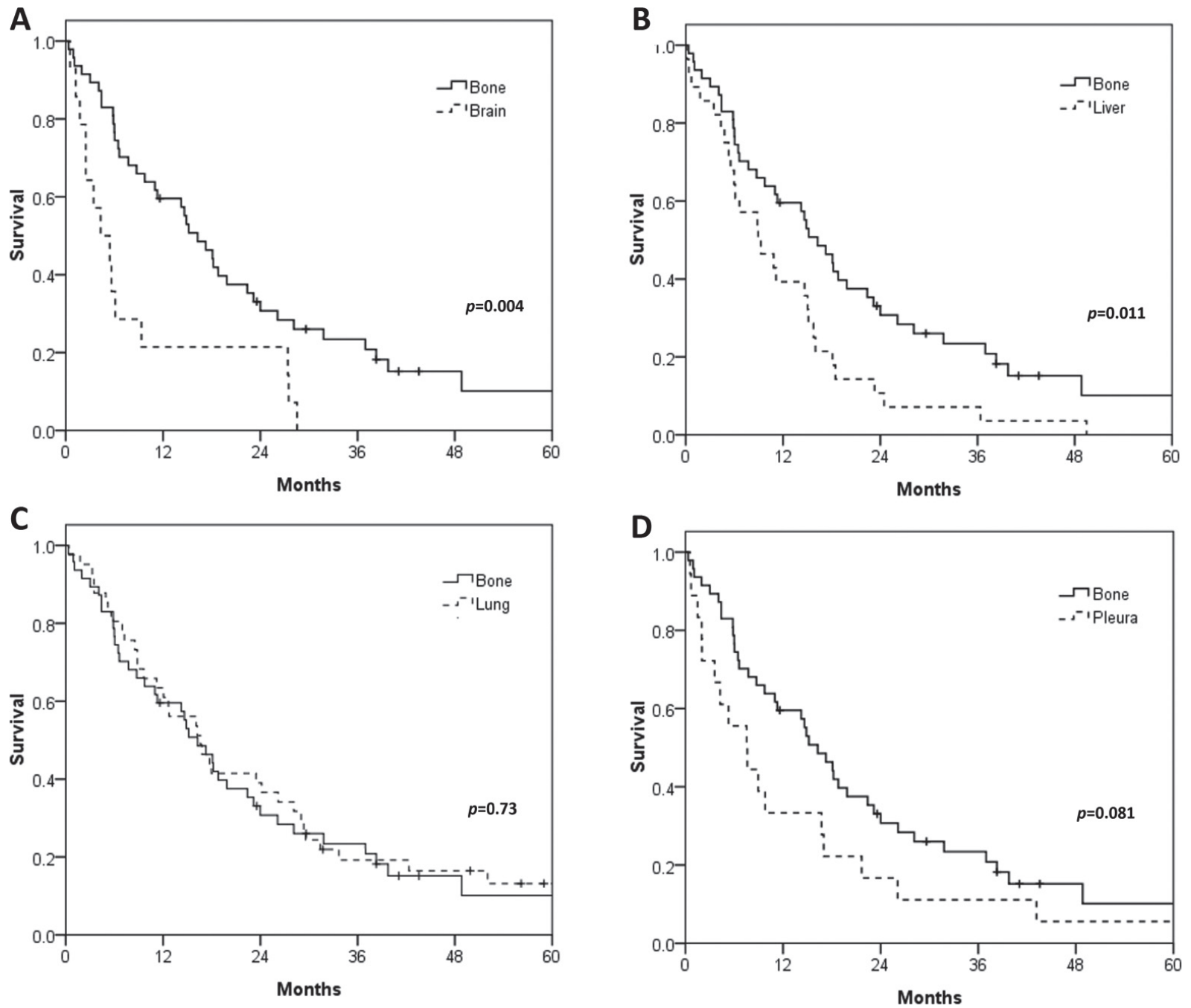

Figure 3. Kaplan-Meier overall survival (OS) curves for triple-negative breast cancer patients as a function of first metastatic site. A) bone versus brain $\mathrm{B}$ ) bone versus liver $\mathrm{C}$ ) bone versus lung $\mathrm{D}$ ) bone versus pleura.

\section{Discussion}

Breast cancer of the triple-negative phenotype is associated with poor survival $[5,7,8,20,22,23]$. The adverse prognosis of TNBC is in large part the result of the excess risk of developing visceral metastases [7, 21]. It has been reported that while the rate of bone metastases was comparable for TNBC and for the other breast cancer subtypes, TNBC patients are four times more likely to develop visceral metastases than patients with non-TNBC subtypes [21]. It is thought that once a patient develops distant metastatic disease, variables other than the number of organ sites and the location involved have no bearing on outcome and that patients with visceral disease generally have a poor outcome. The current investigation focused on the survival differences in patients with different first metastatic organ. The analysis on this cohort of TNBC patients revealed that, of the first-affected organs, patients with brain metastases had the shortest median post-metastatic OS of 4.3 months. Survival rates of patients after the first distant metastatic spread were comparable for bone and lung. TNBC patients with brain and liver metastases had poorer survival than those with bone and lung metastases. Pleural metastases in patients were also associated with unfavorable survival outcome compared to lung metastases. There was a trend toward poorer survival in patients with pleura compared with bone metastases, though statistical significance was not reached. Taken together, these data indicated that the route of first metastasis correlated significantly with survival of TNBC patients with distant metastases to the brain being the poorest survival indicator, followed by liver, pleura, bone, and lung.

Acknowledgements: This work is supported by Bristol-Myers Squibb (Taiwan) Ltd. 


\section{References}

[1] PEROU CM, SORLIE T, EISEN MB, VAN DE RIJN M, JEFFREY SS et al: Molecular portraits of human breast tumours. Nature 2000; 406: 747-752. http://dx.doi.org/10.1038/ $\underline{35021093}$

[2] SORLIE T, TIBSHIRANI R, PARKER J, HASTIE T, MARRON JS et al: Repeated observation of breast tumor subtypes in independent gene expression data sets. Proceedings of the National Academy of Sciences of the United States of America 2003; 100: 8418-8423.

[3] CHANG HY, NUYTEN DS, SNEDDON JB, HASTIE T, TIBSHIRANI R et al: Robustness, scalability, and integration of a wound-response gene expression signature in predicting breast cancer survival. Proceedings of the National Academy of Sciences of the United States of America 2005; 102: 3738-3743. http://dx.doi.org/10.1073/pnas.0409462102

[4] NAUME B, ZHAO X, SYNNESTVEDT M, BORGEN E, RUSSNES HG et al: Presence of bone marrow micrometastasis is associated with different recurrence risk within molecular subtypes of breast cancer. Molecular oncology 2007; 1: 160-171. http://dx.doi.org/10.1016/j.molonc.2007.03.004

[5] CAREY LA, DEES EC, SAWYER L, GATTI L, MOORE DT et al: The triple negative paradox: primary tumor chemosensitivity of breast cancer subtypes. Clin Cancer Res 2007; 13: 2329-2334. http://dx.doi.org/10.1158/1078-0432.CCR-06-1109

[6] LIEDTKE C, MAZOUNI C, HESS KR, ANDRE F, TORDAI A et al: Response to neoadjuvant therapy and long-term survival in patients with triple-negative breast cancer. J Clin Oncol 2008; 26: 1275-1281. http://dx.doi.org/10.1200/ LCO.2007.14.4147

[7] DENT R, TRUDEAU M, PRITCHARD KI, HANNA WM, KAHN HK et al: Triple-negative breast cancer: clinical features and patterns of recurrence. Clin Cancer Res 2007; 13: 44294434. http://dx.doi.org/10.1158/1078-0432.CCR-06-3045

[8] HAFFTY BG, YANG Q, REISS M, KEARNEY T, HIGGINS SA et al: Locoregional relapse and distant metastasis in conservatively managed triple negative early-stage breast cancer. J Clin Oncol 2006; 24: 5652-5657. http://dx.doi.org/10.1200/ $\underline{\mathrm{LCO} .2006 .06 .5664}$

[9] KREIKE B, VAN KOUWENHOVE M, HORLINGS H, WEIGELT B, PETERSE $\mathrm{H}$ et al: Gene expression profiling and histopathological characterization of triple-negative/basal-like breast carcinomas. Breast Cancer Res 2007; 9: R65. http://dx.doi.org/10.1186/bcr1771

[10] PAL SK, MORTIMER J: Triple-negative breast cancer: novel therapies and new directions. Maturitas 2009; 63: 269-274. http://dx.doi.org/10.1016/j.maturitas.2009.06.010

[11] YAMAMOTO Y, IWASE H: Clinicopathological features and treatment strategy for triple-negative breast cancer. Int J Clin Oncol 2010; 15: 341-351. http://dx.doi.org/10.1007/s10147010-0106-1

[12] PODO F, BUYDENS LM, DEGANI H, HILHORST R, KLIPP $\mathrm{E}$ et al: Triple-negative breast cancer: present challenges and new perspectives. Molecular oncology 2010; 4: 209-229. http://dx.doi.org/10.1016/j.molonc.2010.04.006

[13] RAKHA EA, REIS-FILHO JS, ELLIS IO: Basal-like breast cancer: a critical review. J Clin Oncol 2008; 26: 2568-2581. http://dx.doi.org/10.1200/JCO.2007.13.1748

[14] KASSAM F, ENRIGHT K, DENT R, DRANITSARIS G, MYERS J et al: Survival outcomes for patients with metastatic triple-negative breast cancer: implications for clinical practice and trial design. Clin Breast Cancer 2009; 9: 29-33. http://dx.doi.org/10.3816/CBC.2009.n.005

[15] MAKI DD, GROSSMAN RI: Patterns of disease spread in metastatic breast carcinoma: influence of estrogen and progesterone receptor status. AJNR Am J Neuroradiol 2000; 21: 1064-1066.

[16] TSUDA H, TAKARABE T, HASEGAWA F, FUKUTOMI T, HIROHASHI S: Large, central acellular zones indicating myoepithelial tumor differentiation in high-grade invasive ductal carcinomas as markers of predisposition to lung and brain metastases. Am J Surg Pathol 2000; 24: 197-202. http:// dx.doi.org/10.1097/00000478-200002000-00005

[17] HICKS DG, SHORT SM, PRESCOTT NL, TARR SM, COLEMAN KA et al: Breast cancers with brain metastases are more likely to be estrogen receptor negative, express the basal cytokeratin CK5/6, and overexpress HER2 or EGFR. Am J Surg Pathol 2006; 30: 1097-1104. http://dx.doi.org/10.1097/01. pas.0000213306.05811.b9

[18] ALBIGES L, ANDRE F, BALLEYGUIER C, GOMEZ-ABUIN G, CHOMPRET A et al: Spectrum of breast cancer metastasis in BRCA1 mutation carriers: highly increased incidence of brain metastases. Ann Oncol 2005; 16: 1846-1847. http:// dx.doi.org/10.1093/annonc/mdi351

[19] FULFORD LG, REIS-FILHO JS, RYDER K, JONES C, GILLETT CE et al: Basal-like grade III invasive ductal carcinoma of the breast: patterns of metastasis and long-term survival. Breast Cancer Res 2007; 9: R4. http://dx.doi.org/10.1186/ bcr1636

[20] RODRIGUEZ-PINILLA SM, SARRIO D, HONRADO E, HARDISSON D, CALERO F et al: Prognostic significance of basal-like phenotype and fascin expression in node-negative invasive breast carcinomas. Clin Cancer Res 2006; 12: 1533-1539. http://dx.doi.org/10.1158/1078-0432.CCR-05$\underline{2281}$

[21] DENT R, HANNA WM, TRUDEAU M, RAWLINSON E, SUN P et al: Pattern of metastatic spread in triple-negative breast cancer. Breast Cancer Res Treat 2009; 115: 423-428. http://dx.doi.org/10.1007/s10549-008-0086-2

[22] CAREY LA, PEROU CM, LIVASY CA, DRESSLER LG, COWAN D et al: Race, breast cancer subtypes, and survival in the Carolina Breast Cancer Study. JAMA 2006; 295: 2492-2502. http://dx.doi.org/10.1001/jama.295.21.2492

[23] BANERJEE S, REIS-FILHO JS, ASHLEY S, STEELE D, ASHWORTH A et al: Basal-like breast carcinomas: clinical outcome and response to chemotherapy. J Clin Pathol 2006; 59: 729-735. http://dx.doi.org/10.1136/jcp.2005.033043 